Original Article (short paper)

\title{
Ischemic preconditioning delays the time of exhaustion in cycling performance during the early but not in the late phase
}

\author{
Rhaí André Arriel ${ }^{1}$ (1), Hiago Leandro Rodrigues de $\operatorname{Souza}^{1}{ }^{\circledR}$, \\ Bruno Victor Corrêa da Silva ${ }^{2}\left(\mathbb{0}\right.$, Moacir Marocolo $^{1}$ \\ ${ }^{1}$ Universidade Federal de Juiz de Fora, UFJF, Juiz de Fora, MG, Brazil; \\ ${ }^{2}$ Centro Universitário de Belo Horizonte, Uni-BH, Belo Horizonte, MG, Brazil
}

\begin{abstract}
Aims: To investigate the early and late ischemic preconditioning (IPC) effect on the trained cyclists' performance during incremental cycling test until exhaustion. Methods: Twenty-one male cyclists allocated to an IPC ( $2 \times 5$-min of blood flow occlusion at $50 \mathrm{~mm} \mathrm{Hg}$ above systolic pressure followed +5 -min of deflation), SHAM ( 2 x 5-min at $20 \mathrm{~mm} \mathrm{Hg}$ ) or control (CON; no occlusion) interventions, performed three incremental cycling test (ICT) until exhaustion on separate days. The ICT were conducted pre interventions (baseline), 5-min and 24-h after interventions. The heart rate (HR) and power output (PO) were recorded during all ICT. Results: The IPC group increased ICT performance $(4.4 \pm 4.0 \%$; effect size $(\mathrm{ES})=0.27) 5$-min post intervention, accompanied by HR mean reduction, compared to baseline $(\mathrm{p}<0.05)$. However, there were no changes in SHAM $(2.2 \pm 4.2 \%$; ES $=0.07)$ and $\mathrm{CON}(2.9 \pm 5.0 \% ; \mathrm{ES}=0.06)$ groups. In $24-\mathrm{h}$ post intervention, $\mathrm{SHAM}(0.2 \pm 4.7 \% ; \mathrm{ES}=0.02)$ and $\mathrm{CON}(-1.0 \pm 1.6$; $\mathrm{ES}=0.03)$ maintained $(\mathrm{p}>0.05)$ and IPC group decreased the performance $(-4.6 \pm 3.6 \%$; ES $=0.16)$ compared to 5 -min post intervention $(p<0.05)$, but all groups were similar to baseline $(p>0.05)$. There were no difference $(p>0.05)$ among groups for PO peak, HR and ICT performance in all moments (baseline, 5-min and 24-h post intervention). Conclusion: The IPC increases early but not late incremental cycling test performance.
\end{abstract}

Keywords: Ischemia/reperfusion, hyperemia, heart rate, cycling exercise.

\section{Introduction}

Beyond to the benefits of physical training, the exploration of the preconditioning strategies on the day of competition to enhance physical performance have increasingly aroused of sports researchers ${ }^{1,2}$. Considered as non-invasive, inexpensive and easy-to-apply strategy ${ }^{3}$, brief ischemia cycles followed by reperfusion in certain body limbs, known as ischemic preconditioning (IPC), showed effectiveness on the improvement exercise performance, mainly dependent on the aerobic energy system when applied minutes before exercise ${ }^{4}$. In this time window (begins immediately after reperfusion and lasts 3-4 hours; early phase ${ }^{5}$ ) researchers suggest that IPC cause an aerobic performance improvement due to increase oxygen extraction ${ }^{6}$ or faster uptake of acetyl coenzyme A by mitochondria, increasing the aerobically generate adenosine triphosphate (ATP) for exercise ${ }^{7}$.

On the other hand, clinical research ${ }^{5}$ suggests that IPC effects result also in a second phase, known as late phase or "second window", which begins 12-24 hours after IPC intervention. In this phase, IPC cause an increase iNOS (one isoform of nitric oxide (NO) synthase) level ${ }^{8}$ and may produce $\mathrm{NO}$, which was suggested for decrease the ATP cost of muscle force production ${ }^{9}$, perhaps via increased mitochondrial efficiency ${ }^{10}$. Thus, both early and late IPC phases could aid to increase exercise performance in the first and consecutive days of competition. In early phase, the IPC showed benefits on power output (W max) and performance during maximal incremental cycling test (ICT) in physically active subjects ${ }^{3,11}$. However, the IPC late phase has not yet been clearly elucidated ${ }^{12,13}$. Therefore, the current study aimed to investigate the early and late IPC phase's effect on the trained cyclists' performance during two consecutive days. We hypothesized that both early and late IPC phases will increase the maximal ICT performance.

\section{Methods}

\section{Participants}

Twenty-one male cyclists (Table 1) volunteered in this study that was approved by the local ethical committee (N. 2.250.458/2017) for human experiments and was performed in accordance with the Declaration of Helsinki (2000). All cyclists were healthy and trained. To be included in the study, cyclists needed to be able to reach the criteria for classification of trained level according to the study of Jeukendrup, Craig and Hawley ${ }^{14}$. The exclusion criteria were: i) have any cardiovascular or metabolic disease; ii) use of the caffeine supplement; iii) use of exogenous drugs, anabolicandrogenic steroids or any potentially substance that could promote improvement in exercise performance; iv) smoking history and v) musculoskeletal, bone or joint injury that could limit the execution of the proposed exercise. This information 
were identified in the participants' self-reports. Before the tests, the subjects giving their consent and were informed about the risks and procedures.

Table 1. General characteristics of subjects

\begin{tabular}{cc}
\hline Characteristics & \\
\hline Age (years) & $28.4 \pm 4.5$ \\
Height $(\mathrm{cm})$ & $80.5 \pm 10.4$ \\
Body mass $(\mathrm{Kg})$ & $16.7 \pm 4.0$ \\
Body fat $(\%)$ & $317.3 \pm 45.6$ \\
PO $_{\text {peak }}(\mathrm{W})$ & $4.0 \pm 0.6$ \\
PO $_{\text {peak }}\left(\mathrm{W} \cdot \mathrm{Kg}{ }^{-1}\right)$ & \\
\hline Training History & $3.1 \pm 1.5$ \\
\hline Experience (years) & $4.9 \pm 1.6$ \\
\hline Hours per week &
\end{tabular}

Data are mean $\pm \mathrm{SD}$. PO = power output in incremental cycling test.

\section{Experimental design}

This study was a single-blind (i.e. the tester was blind to the protocol interventions "received" by each cyclist) trial with SHAM, IPC and control interventions. According to counterbalanced peak power $\left(\mathrm{W} . \mathrm{Kg}^{-1}\right)$ reached in the ICT, the cyclists were allocated into one of three interventions. They attended on four different days (48-, 48- and 24-h intervals respectively), at the same time of the day to prevent circadian influences ${ }^{15}$. The tests were performed under monitored environment $\left(23.1 \pm 1.6^{\circ} \mathrm{C}\right.$; relative humidity: $\left.79.2 \pm 7.6 \%\right)$. At the first visit, cyclists were instructed to maintain their regular feeding routine, replicate then during the days of experiment, and did not perform moderate or intense physical exercise 48-h before the second visit ${ }^{16}$. In addition, the anthropometric measurements and familiarization with perceptual scales were carried out. On the second visit, the recovery level of cyclists was checked and they performed the baseline ICT. After 48-h, at the third visit, again the recovery level was checked, applied IPC, SHAM or CON intervention and, 5-min after, was performed the ICT. The pain perception from IPC or SHAM application was evaluated immediately after the end of the application.To balance of information level and prevent the possible placebo and/or nocebo effect found in previous studies ${ }^{17,18}$, we informed the cyclists that both interventions (IPC and SHAM) would improve their performance in ICT (5-min and 24-h after the intervention). At the fourth visit, 24-h after IPC, SHAM or CON application, the volunteers repeated the ICT. Figure 1 shows the experimental design of the study.

\section{Ischemic preconditioning}

For the IPC and SHAM intervention was used a traditional nylon blood pressure cuff $(77 \times 21.5)$ applied around the subinguinal region of the upper thigh. The IPC intervention was based on the study of Ghosh, Standen and Galiñanes ${ }^{19}$, and consisted by 2 cycles of 5-min occlusion/5-min of reperfusion. The pressure cuff applied was $50 \mathrm{mmHg}$ above systolic arterial pressure followed by $0 \mathrm{~mm} \mathrm{Hg}$ during reperfusion phase ${ }^{20}$. The occlusion and reperfusion phases were conducted alternately between the thighs, with subjects remaining in supine rest position. The SHAM intervention was identical to IPC interventions but with an absolute pressure of $20 \mathrm{~mm} \mathrm{Hg}$ during the "occlusion phases"21. During the inflation and deflation phases of the IPC and SHAM, the blood flow was constantly checked by auscultation of the tibial anterior artery to confirmed occlusion/reperfusion phases properly ${ }^{18}$. The total duration of intervention (IPC and SHAM) was 20 minutes. The volunteers of control group spent the same time in rest without cuffs.

\section{Pain measurement and perceived recovery status}

The pain assessment of the IPC and SHAM interventions were performed after the application through a visual analogue scale $(\mathrm{VAS})^{22}$. The VAS contained numbers with values between $0-10$ and markings where: 0 is no pain; $1-2$ mild pain; 3-7 moderate pain; and 8-10 severe pain. To ensure that cyclists were in the same recovery condition ${ }^{23}$, the cyclists' recovery level was evaluated through the perceived recovery scale $(\mathrm{PR})^{24}$, before all ICT.

Figure 1. Experimental Design of the study. ICT = Incremental cycling test; IPC = Ischemic preconditioning $(n=7) ; \mathrm{SHAM}=$ cuff administration with lower pressure $(n=7)$; $\mathrm{CON}=\mathrm{Control}(\mathrm{n}=7)$.

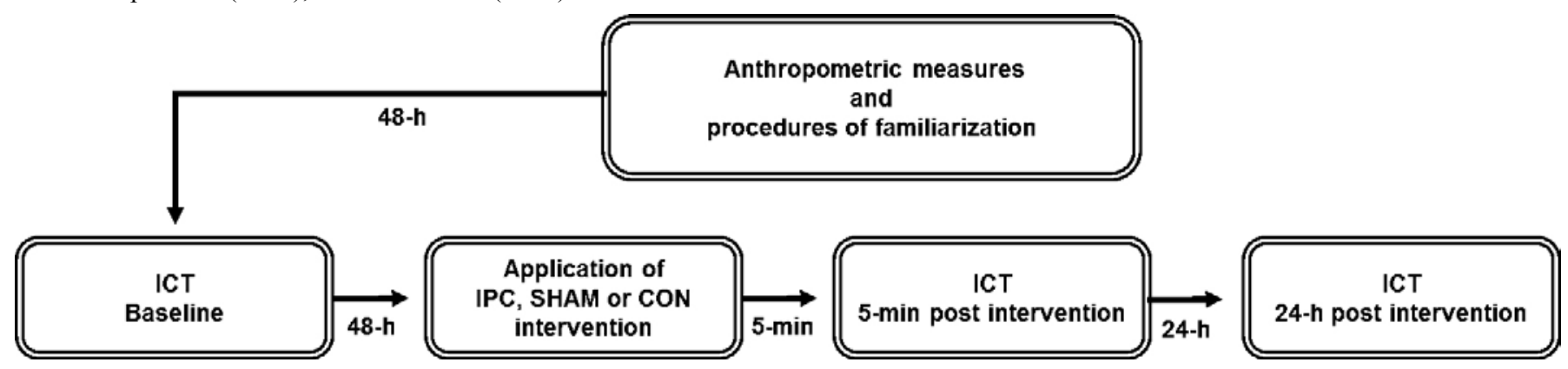




\section{Incremental cycling test (ICT)}

All ICTs were performed in the same cycle ergometer (Monark 839 E, Sweden). The cycle ergometer setup (saddle and handlebar) were performed by the cyclists themselves and individually kept during all tests. A 4-minute warm-up at $40 \mathrm{~W}$ was carried out. The ICT power was initiated at $40 \mathrm{~W}$, increasing by $20 \mathrm{~W} / \mathrm{min}$ until voluntary exhaustion and keeping a constant cadence of $80-90 \mathrm{rpm}^{3,11}$. The test was interrupted when the cyclist was unable to maintain the cadence for more than 5 seconds or stopped voluntarily. Previous study ${ }^{25}$ have suggested a variation of the $2.6 \%$ in ICT performance, using fixed methods. Besides is a test well-established and often used in research ${ }^{3,11,26}$, the psychophysiological variables evaluated by ICT are highly correlated with cycling performance ${ }^{26}$.

\section{Power output, heart rate and perceived exertion}

During all the ICTs, the power output (PO), heart rate (HR) (Polar ${ }^{\circledR}$, RS800CX, Finland) and rate of perceived exertion (RPE) adapted to cycling ${ }^{27}$ were recorded at the last 10 seconds of each stage.

\section{Statistical analysis}

The normality of the data was tested using the Shapiro-Wilk test. Two-way analysis of variance (ANOVA) was conducted for intergroup difference analysis at baseline, 5-min post-and 24-h post-intervention, followed by Bonferroni's post-hoc test. For measurements in the correlations between Power output and heart rate, the Pearson's bivariate correlation test was performed. An independent Student t-test was used for IPC and SHAM intervention soreness comparisons. The effect size (ES) was calculated and the magnitude was classified as trivial $(<0.2)$, small $(>0.2-0.6)$, moderate $(>0.6-1.2)$, large $(>1.2)$ as recommended ${ }^{28}$. Level of significance was of the 0.05 . Data are presented as mean and standard deviation. The statistical program used to analyze the data was GraphPad (PRISM $^{\circledR}$, 6.0, San Diego, USA).

\section{Results}

All cyclists completed the four days of testing and reported no significant difference $(p>0.05)$ in PR (Table 2). The pain measurement showed significantly higher values $(p<0.05)$ in IPC $(4.7 \pm 2.1)$ compared to SHAM $(0.1 \pm 0.4)$ group.
The Figure 2 shows that IPC group increased performance $(33.3 \pm 29.4 \mathrm{~s} ; 4.4 \pm 4.0 \% ; \mathrm{p}=0.022 ; \mathrm{ES}=0.27$; small $)$ 5 -min post-intervention compared baseline. SHAM (17.4 \pm $32.4 \mathrm{~s} ; 2.2 \pm 4.2 \% ; \mathrm{p}=0.613 ; \mathrm{ES}=0.07$; trivial) and $\mathrm{CON}$ $(23.3 \pm 39.2 \mathrm{~s} ; 2.9 \pm 5.0 \% ; \mathrm{p}=0.502 ; \mathrm{ES}=0.06$; trivial $)$ groups also improvement ICT performance, but were not significant ( $p>0.05)$, compared to baseline. There was not difference in the time change (delta) between baseline and 5 -min post intervention among groups $(\mathrm{p}=0.682)$. In 24 -h post intervention, IPC group decreased the ICT performance $(-37.8 \pm 29.7 \mathrm{~s} ;-4.6 \pm 3.6 \% ; \mathrm{p}=0.009 ; \mathrm{ES}=0.16$; trivial $)$ compared 5-min post intervention (Figure 2) and this reduction in the time change (delta) was significantly greater than SHAM $(\mathrm{p}=0.043)$. Moreover, $\mathrm{CON}(-8.1 \pm 15.0 \mathrm{~s} ;-1.0 \pm 1.6 \% ; \mathrm{p}=$ 0.603 ; $\mathrm{ES}=0.05$; trivial) group decreased ICT performance, but SHAM $(3.3 \pm 36.3 \mathrm{~s} ; 0.2 \pm 4.7 \% ; \mathrm{p}=1.0 ; \mathrm{ES}=0.03$; trivial) group showed a small improvement. However, both were not significant. Finally, in 24-h post intervention, IPC, SHAM and CON were not different to baseline $(p>0.05)$. The Figure 3 shows individual cyclists' ICT performance in baseline, 5-min and 24-h post intervention.

The mean HR was lower $(p=0.002)$ after 5 -min but not 24-h post IPC intervention. Non-significant differences ( $p$ $>0.05$ ) were found for other parameters (i.e., HR and Power) as it could be noted in Table 2. Additionally, non-significant correlations $(p>0.05)$ were found among variables.

Figure 2. Time to exhaustion of incremental cycling test in baseline, 5-min (5-min post) and 24-h (24-h post) post interventions. IPC = Ischemic preconditioning $(\mathrm{n}=7)$; SHAM = cuff administration with lower pressure $(n=7)$; $\mathrm{CON}=\operatorname{Control}(n=7)$.

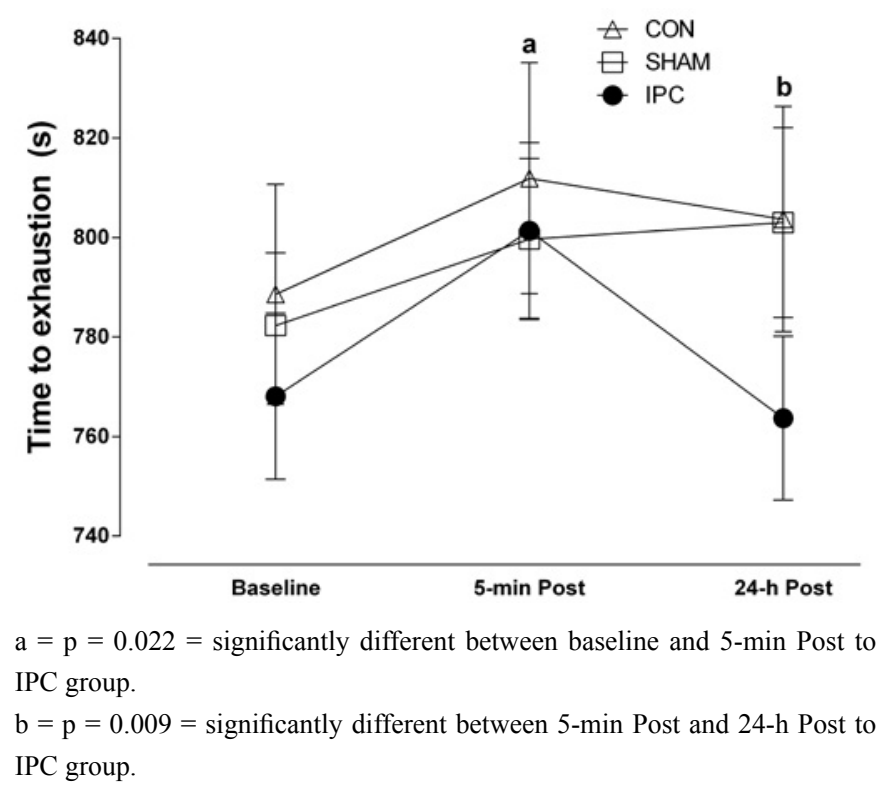


Figure 3. Individual time to exhaustion of incremental cycling test in baseline, 5-min (5-min post) and 24-h (24-h post) post interventions. IPC = Ischemic preconditioning; SHAM = cuff administration with lower pressure; $\mathrm{CON}=$ Control.
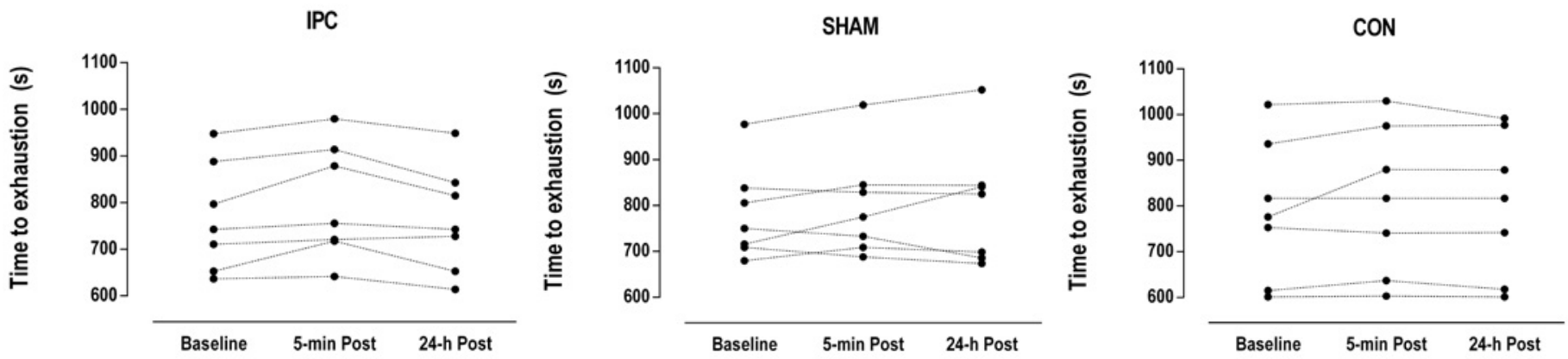

Table 2. Results of incremental cycling test in baseline, 5-min (5-min post) and 24-h (24-h post) post interventions.

\begin{tabular}{cccccccc}
\hline Groups & & HRMean $(\mathbf{b p m})$ & HRMax $(\mathbf{b p m})$ & POMean (W) & POPeak (W) & POPeak (W.Kg) & PR (0-10) \\
\hline \multirow{2}{*}{ IPC } & Baseline & $157 \pm 3$ & $197 \pm 3$ & $151.4 \pm 19.5$ & $315.2 \pm 16.8$ & $4.0 \pm 0.4$ & $7.2 \pm 0.6$ \\
$(\mathrm{n}=7)$ & 5-min post & $150 \pm 3 *$ & $197 \pm 4$ & $160.0 \pm 20.8$ & $319.7 \pm 16.4$ & $4.0 \pm 0.3$ & $7.0 \pm 0.7$ \\
& 24-h post & $151 \pm 4$ & $194 \pm 2$ & $152.9 \pm 18.9$ & $306.1 \pm 16$ & $3.9 \pm 0.4$ & $7.6 \pm 0.7$ \\
& Baseline & $151 \pm 4$ & $192 \pm 3$ & $155.7 \pm 19.0$ & $315.6 \pm 12.2$ & $4.0 \pm 0.9$ & $8.1 \pm 0.5$ \\
SHAM & 5-min post & $152 \pm 4$ & $196 \pm 3$ & $158.6 \pm 21.2$ & $324.7 \pm 13$ & $4.1 \pm 0.9$ & $8.3 \pm 0.4$ \\
$(\mathrm{n}=7)$ & 24-h post & $150 \pm 5$ & $192 \pm 4$ & $160.0 \pm 22.4$ & $323.3 \pm 16.9$ & $4.0 \pm 1.1$ & $7.3 \pm 0.4$ \\
& Baseline & $152 \pm 4$ & $192 \pm 5$ & $157.1 \pm 25.6$ & $321.4 \pm 22.8$ & $4.1 \pm 0.7$ & $8.6 \pm 0.6$ \\
CON & 5-min post & $149 \pm 5$ & $195 \pm 5$ & $161.4 \pm 27.3$ & $334.2 \pm 25$ & $4.2 \pm 0.7$ & $7.9 \pm 0.7$ \\
$(\mathrm{n}=7)$ & 24-h post & $145 \pm 5$ & $191 \pm 4$ & $160.0 \pm 25.2$ & $327.2 \pm 21.5$ & $4.1 \pm 0.7$ & $7.9 \pm 0.8$ \\
\hline
\end{tabular}

$\mathrm{HR}=$ heart rate; $\mathrm{PO}=$ power output; $\mathrm{PR}=$ perceived recovery; $\mathrm{n}=$ sample size per group. Date are mean $\pm \mathrm{SD}$. IPC $=$ Ischemic preconditioning; SHAM = cuff administration with lower pressure; $\mathrm{CON}=\mathrm{Control}$.

$* p=0.002=$ significantly different from IPC baseline.

\section{Discussion}

In this study, we evaluated the early (5-min post intervention) and late (24-h post intervention) IPC effect on ICT performance and physiological parameters in trained cyclists. The main finding was that only the early phase produced a positive effect on ICT performance as well as significantly reduced the mean HR. Corroborating our data, recent studies reported improvements in incremental cycling test performance of highly trained $(1.6 \%)^{3}$ and recreationally active subjects $(3.7 \%)^{11} 5$-min after IPC intervention, which indicates that our performance increments of $4.4 \%$ are in line with scientific literature. Our higher beneficial effects compared with another experiment ${ }^{3}$, could be due a different training level, since they evaluated a highly trained cyclists, while our study analyzed only trained cyclists. It could be speculated that responsiveness to IPC is related with the training level ${ }^{29}$.

It could be noted in Figure 3 that all subjects increased their time to exhaustion 5-min after IPC while their response 24-h later was non-homogeneous ( 1 present better and 6 worse performance). The SHAM and Control group presented a different pattern, with the same or weak performance both after 5-min and 24-h intervention. This response are in line with a previous study ${ }^{30}$ which also showed a non-consensus performance patter in recreational swimmers (some of them increased while others reduced 100-m time trial).

Although the IPC mechanisms are still unclear, poorly understood and under-investigation, it has been reported that the intervention resulted in vasodilation ${ }^{31}$, increased oxygen extraction $^{32}$ and speculation of faster uptake of acetyl-CoA (a breakdown product of glycolysis) by mitochondria ${ }^{7}$, facilitating the increase of the aerobic contribution during physical exercise. In addition, improving the efficiency of the excitation-contraction coupling ${ }^{33}$, maintaining the frequency of rapid force development.

Moreover, the IPC intervention is associated with an NO increase, which reduces the reactive oxygen species (ROS) amount through modulation mitochondrial ROS level or reacting with $\operatorname{ROS}^{34}$. These species, which increase during strenuous exercise, are known by play a causal role in contractile muscle function resulting in muscle fatigue ${ }^{35}$, and their reduction resulted in a delay of this fatigue during a maximal incremental cycling test $\mathrm{t}^{36}$. It is suggested that ROS promote a delay in calcium reuptake intracellular ${ }^{37}$, decreasing calcium-activated force of muscle myofilaments ${ }^{38}$. Therefore, our findings suggest that IPC intervention could to reduce ROS generation during ICT, delaying skeletal muscle fatigue and improving performance.

A recent meta-analysis showed that some IPC studies improved performance, but did not present significant physiological 
changes $^{39}$. Thus, we monitored the HR during the ICT, which is a popular method for measuring exercise intensity ${ }^{40}$, and we found a reduction of the HR mean (Table 2) 5-min after IPC intervention probably associated with performance improvement. As there is a linear relationship between heart rate and work rate $^{40}$, we speculate that this HR mean attenuation during ICT can indicate a less effort for the same workload compared the baseline, without change precipitately any factor related to the fatigue ${ }^{41}$, such as ROS generation. However, there was no relation between mean power output and mean HR.

Clinical research suggests that the IPC effects result in two phases 5 . The early phase, "first window" of protection, which starts soon after reperfusion and lasts 3 - 4 hours; and late phase, "second window", which begins 12-24 hours after intervention. Crisafulli, Tangianu, Tocco, Concu, Mameli and Mulliri ${ }^{11}$ found improvements in the time to exhaustion of an incremental cycling test soon after IPC intervention. However, the IPC late phase on physical performance has not yet been clearly elucidated. It is believed that the IPC intervention effect is amplified (i.e. later phase) by recruiting several complex pathways of signal transduction (such as adenosine, bradykinin, opioids, cytokines or nitric oxide [NO]) recruited on the same day of IPC stimulus, which in turn activate transcription factors, resulting in the synthesis 12-24 h later of 'distal mediators' such as $\mathrm{iNOS}^{42}$. The iNOS (one isoform of NO synthase) ${ }^{8}$ can produce NO, which was suggested for decrease the ATP cost of muscle force production ${ }^{9}$, perhaps via increased mitochondrial efficiency ${ }^{10}$. Two studies investigated the IPC effect in early ${ }^{13}$ and late phases ${ }^{12,13}$. One on swimming performance in the 100 and 200 meters time trial1 3 and another on cycling performance during an incremental cycling test ${ }^{12}$.

This research has some limitations. We did not measure ROS markers such as oxidants or antioxidants to assess oxidative stress. These markers can be important to identify a possible IPC effect on muscle fatigue in endurance exercise ${ }^{36}$. Moreover, the lack of other aerobic measures (such as VO2max, blood lactate concentration, muscle oxygenation measurement) to check a possible improvement on performance. These are plausible pathways to future studies.

\section{Conclusion}

Our findings support a beneficial effect of ischemic preconditioning during early phase while this improvement was not present during the late phase. In addition, a small effect size for time to exhaustion was found, which should be carefully analyzed when considering the possibility of this intervention as an ergogenic aid.

\section{References}

1. Kilduff LP, Finn CV, Baker JS, Cook CJ, West DJ. Preconditioning strategies to enhance physical performance on the day of competition. Int J Sports Physiol Perform. 2013 Nov;8(6):677-81.
2. Russell M, West DJ, Harper LD, Cook CJ, Kilduff LP. Half-time strategies to enhance second-half performance in team-sports players: a review and recommendations. Sports Med Auckl NZ. 2015 Mar;45(3):353-64.

3. de Groot PCE, Thijssen DHJ, Sanchez M, Ellenkamp R, Hopman MTE. Ischemic preconditioning improves maximal performance in humans. Eur J Appl Physiol. 2010 Jan;108(1):141-6.

4. Incognito AV, Burr JF, Millar PJ. The Effects of Ischemic Preconditioning on Human Exercise Performance. Sports Med Auckl NZ. 2016 Apr;46(4):531-44.

5. Loukogeorgakis SP, Panagiotidou AT, Broadhead MW, Donald A, Deanfield JE, MacAllister RJ. Remote ischemic preconditioning provides early and late protection against endothelial ischemia-reperfusion injury in humans: role of the autonomic nervous system. J Am Coll Cardiol. 2005 Aug 2;46(3):450-6.

6. Kido K, Suga T, Tanaka D, Honjo T, Homma T, Fujita S, et al. Ischemic preconditioning accelerates muscle deoxygenation dynamics and enhances exercise endurance during the work-to-work test. Physiol Rep. 2015 May;3(5).

7. Jean-St-Michel E, Manlhiot C, Li J, Tropak M, Michelsen MM, Schmidt MR, et al. Remote preconditioning improves maximal performance in highly trained athletes. Med Sci Sports Exerc. $2011 \mathrm{Jul} ; 43(7): 1280-6$.

8. Wang G, Li X, Wang H, Wang Y, Zhang L, Zhang L, et al. Later phase cardioprotection of ischemic post-conditioning against ischemia/reperfusion injury depends on iNOS and PI3K-Akt pathway. Am J Transl Res. 2015;7(12):2603-11.

9. Bailey SJ, Fulford J, Vanhatalo A, Winyard PG, Blackwell JR, DiMenna FJ, et al. Dietary nitrate supplementation enhances muscle contractile efficiency during knee-extensor exercise in humans. J Appl Physiol Bethesda Md 1985. 2010 Jul;109(1):135-48.

10. Larsen FJ, Schiffer TA, Borniquel S, Sahlin K, Ekblom B, Lundberg JO, et al. Dietary inorganic nitrate improves mitochondrial efficiency in humans. Cell Metab. 2011 Feb 2;13(2):149-59.

11. Crisafulli A, Tangianu F, Tocco F, Concu A, Mameli O, Mulliri G, et al. Ischemic preconditioning of the muscle improves maximal exercise performance but not maximal oxygen uptake in humans. J Appl Physiol Bethesda Md 1985. 2011 Aug;111(2):530-6.

12. Arriel RA, de Souza HLR, da Mota GR, Marocolo M. Declines in exercise performance are prevented 24 hours after postexercise ischemic conditioning in amateur cyclists. PloS One. 2018 Nov;13(11):e0207053.w

13. Williams N, Russell M, Cook CJ, Kilduff LP. The Effect of Ischemic Preconditioning on Maximal Swimming Performance. J Strength Cond Res. 2018 Jan 30;

14. Jeukendrup AE, Craig NP, Hawley JA. The bioenergetics of World Class Cycling. J Sci Med Sport. 2000 Dec;3(4):414-33.

15. Fernandes AL, Lopes-Silva JP, Bertuzzi R, Casarini DE, Arita DY, Bishop DJ, et al. Effect of time of day on performance, hormonal and metabolic response during a 1000-M cycling time trial. PloS One. 2014;9(10):e109954.

16. da Silva BVC, Simim MA de M, Marocolo M, Franchini E, da Mota GR. Optimal load for the peak power and maximal strength of the upper body in Brazilian Jiu-Jitsu athletes. J Strength Cond Res. 2015 Jun;29(6):1616-21. 
17. Marocolo M, Marocolo IC, da Mota GR, Simão R, Maior AS, Coriolano H-JA. Beneficial Effects of Ischemic Preconditioning in Resistance Exercise Fade Over Time. Int J Sports Med. 2016 Sep;37(10):819-24.

18. Marocolo M, Willardson JM, Marocolo IC, Ribeiro da Mota G, Simão R, Maior AS. Ischemic Preconditioning and Placebo Intervention Improves Resistance Exercise Performance. J Strength Cond Res Natl Strength Cond Assoc. 2016 May;30(5):1462-9.

19. Ghosh S, Standen NB, Galiñanes M. Preconditioning the human myocardium by simulated ischemia: studies on the early and delayed protection. Cardiovasc Res. 2000 Jan 14;45(2):339-50.

20. Sharma V, Marsh R, Cunniffe B, Cardinale M, Yellon DM, Davidson SM. From Protecting the Heart to Improving Athletic Performance - the Benefits of Local and Remote Ischaemic Preconditioning. Cardiovasc Drugs Ther. 2015 Oct 19;

21. Paixão RC, da Mota GR, Marocolo M. Acute effect of ischemic preconditioning is detrimental to anaerobic performance in cyclists. Int J Sports Med. 2014 Oct;35(11):912-5.

22. Lalonde F, Curnier DY. Can anaerobic performance be improved by remote ischemic preconditioning? J Strength Cond Res. 2015 Jan;29(1):80-5.

23. Marocolo IC, Mota GR da, Londe AM, Patterson SD, Neto OB, Marocolo M. Acute ischemic preconditioning does not influence high-intensity intermittent exercise performance. PeerJ. 2017 Nov 30;5:e4118.

24. Laurent CM, Green JM, Bishop PA, Sjökvist J, Schumacker RE, Richardson MT, et al. A practical approach to monitoring recovery: development of a perceived recovery status scale. J Strength Cond Res Natl Strength Cond Assoc. 2011 Mar;25(3):620-8.

25. Hoefelmann CP, Diefenthaeler F, Costa VP, de Lucas RD, Shambrook P, Guglielmo LGA. Test-retest reliability of second lactate turnpoint using two different criteria in competitive cyclists. Eur J Sport Sci. 2015;15(4):265-70.

26. Impellizzeri FM, Marcora SM, Rampinini E, Mognoni P, Sassi A. Correlations between physiological variables and performance in high level cross country off road cyclists. Br J Sports Med. 2005 Oct;39(10):747-51.

27. Robertson RJ, Goss FL, Dube J, Rutkowski J, Dupain M, Brennan $\mathrm{C}$, et al. Validation of the adult OMNI scale of perceived exertion for cycle ergometer exercise. Med Sci Sports Exerc. 2004 Jan;36(1):102-8.

28. Hopkins WG, Marshall SW, Batterham AM, Hanin J. Progressive statistics for studies in sports medicine and exercise science. Med Sci Sports Exerc. 2009 Jan;41(1):3-13.

29. Tocco F, Marongiu E, Ghiani G, Sanna I, Palazzolo G, Olla $\mathrm{S}$, et al. Muscle ischemic preconditioning does not improve performance during self-paced exercise. Int J Sports Med. 2015 Jan;36(1):9-15.

30. Marocolo M, da Mota GR, Pelegrini V, Appell Coriolano HJ. Are the Beneficial Effects of Ischemic Preconditioning on Performance Partly a Placebo Effect? Int J Sports Med. 2015 Oct;36(10):822-5.

31. Enko K, Nakamura K, Yunoki K, Miyoshi T, Akagi S, Yoshida $\mathrm{M}$, et al. Intermittent arm ischemia induces vasodilatation of the contralateral upper limb. J Physiol Sci JPS. 2011 Nov;61(6):507-13.

32. Kido K, Suga T, Tanaka D, Honjo T, Homma T, Fujita S, et al. Ischemic preconditioning accelerates muscle deoxygenation dynamics and enhances exercise endurance during the work-to-work test. Physiol Rep. 2015 May;3(5).

33. Bailey TG, Jones H, Gregson W, Atkinson G, Cable NT, Thijssen DHJ. Effect of ischemic preconditioning on lactate accumulation and running performance. Med Sci Sports Exerc. 2012 Nov;44(11):2084-9.

34. Raat NJH, Shiva S, Gladwin MT. Effects of nitrite on modulating ROS generation following ischemia and reperfusion. Adv Drug Deliv Rev. 2009 Apr 28;61(4):339-50.

35. Reid MB. Reactive Oxygen Species as Agents of Fatigue. Med Sci Sports Exerc. 2016;48(11):2239-46.

36. De Marchi T, Leal Junior ECP, Bortoli C, Tomazoni SS, LopesMartins RAB, Salvador M. Low-level laser therapy (LLLT) in human progressive-intensity running: effects on exercise performance, skeletal muscle status, and oxidative stress. Lasers Med Sci. 2012 Jan;27(1):231-6.

37. Viner RI, Hühmer AF, Bigelow DJ, Schöneich C. The oxidative inactivation of sarcoplasmic reticulum $\mathrm{Ca}(2+)$-ATPase by peroxynitrite. Free Radic Res. 1996 Apr;24(4):243-59.

38. Andrade FH, Reid MB, Westerblad H. Contractile response of skeletal muscle to low peroxide concentrations: myofibrillar calcium sensitivity as a likely target for redox-modulation. FASEB J Off Publ Fed Am Soc Exp Biol. 2001 Feb;15(2):309-11.

39. Marocolo M, da Mota GR, Simim M a. M, Appell Coriolano H-J. Myths and Facts About the Effects of Ischemic Preconditioning on Performance. Int J Sports Med. 2016 Feb;37(2):87-96.

40. Achten J, Jeukendrup AE. Heart rate monitoring: applications and limitations. Sports Med Auckl NZ. 2003;33(7):517-38.

41. Ament W, Verkerke GJ. Exercise and fatigue. Sports Med Auckl NZ. 2009;39(5):389-422.

42. Hausenloy DJ, Yellon DM. The second window of preconditioning (SWOP) where are we now? Cardiovasc Drugs Ther. 2010 Jun;24(3):235-54.

\section{Corresponding author}

Moacir Marocolo

Mailing address: Rua José Lourenço Kelmer s/n, Postal code: 36036-900 E-mail: isamjf@gmail.com

Manuscript received on June 23, 2018

Manuscript accepted on August 19, 2018

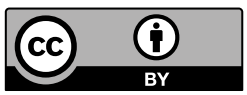

Motriz. The Journal of Physical Education. UNESP. Rio Claro, SP, Brazil - eISSN: 1980-6574 - under a license Creative Commons - Version 3.0 